\title{
Rise of a New Sustainable Urban Mobility Planning Paradigm in Local Governance: Does the SUMP Make a Difference?
}

\author{
Radomíra Jordová and Hana Brůhová-Foltýnová *(D) \\ Faculty of Social and Economic Studies, Jan Evangelista Purkyně University in Ústí nad Labem, \\ Pasteurova 3544/1, 40096 Ústí nad Labem, Czech Republic; radomira.jordova@ujep.cz \\ * Correspondence: hana.bruhova@ujep.cz; Tel.: +420-736-434-347
}

\begin{abstract}
The EU Green Deal sets challenging goals for cities, including a 90\% reduction in Green House Gas (GHG) emissions from transport by 2050. This requires an integrated and coordinated approach to urban mobility planning, represented by Sustainable Urban Mobility Plans (SUMPs), and encouraged by European policies. However, the experience of cities with SUMPs varies substantially among the EU Member States. Using qualitative and quantitative methods of data analysis, this paper aims to explore the institutional settings, practices, and barriers to sustainable mobility in Czech cities and differences between cities with and without a SUMP. The data were collected using interviews and an online questionnaire survey among stakeholders who substantially influence the urban planning praxis. The data reveal that monitoring, evaluation, and public involvement are underestimated by analyzed cities and the perception of a need for a significant transport behavior change is still quite low among local politicians. A SUMP brings substantial benefits to Czech cities of all sizes, even in the initial phase of its implementation. The cities that have developed a SUMP apply various sustainable transport measures more often, create more participation activities, and are better at evaluation than cities without a SUMP.
\end{abstract}

Citation: Jordová, R.;

Brůhová-Foltýnová, H. Rise of a New Sustainable Urban Mobility Planning Paradigm in Local Governance: Does the SUMP Make a Difference? Sustainability 2021, 13, 5950. https:// doi.org/10.3390/su13115950

Academic Editor: Itzhak Benenson

Received: 27 April 2021

Accepted: 20 May 2021

Published: 25 May 2021

Publisher's Note: MDPI stays neutral with regard to jurisdictional claims in published maps and institutional affiliations.

Keywords: sustainable transport planning; monitoring and evaluation; policymaking in cities; Sustainable Urban Mobility Plan; Czech cities

\section{Introduction}

European cities have undoubtedly entered a challenging period regarding their further transport development. They should reflect the EU Green Deal [1], which sets the target of a $90 \%$ reduction in greenhouse gas emissions from transport to reach a climate-neutral economy by 2050. Specific challenges were revealed in the spring of 2020 with the COVID19 epidemics, which accelerated the need to create conditions for safe travel and to adjust the transport systems to new travel patterns (such as an increase in telecommuting, online shopping, and other activities) and new mobility services.

A major responsibility for choosing and implementing appropriate and effective measures and policies lies directly with cities, which poses a significant challenge for responsible (local) governments, institutions and academia [2]. A new concept of integrated sustainable planning with its Sustainable Urban Mobility Plans (SUMPs) (the following definition of a SUMP is widely recognized: "A Sustainable Urban Mobility Plan is a strategic plan designed to satisfy the mobility needs of people and businesses in cities and their surroundings for a better quality of life. It builds on existing planning practices and takes due consideration of integration, participation, and evaluation principles." See the EU guidelines for preparation of SUMPs [3]) reflects these challenges but requires a substantial change in the planning principles of cities. While traditional transport planning has focused on providing space for the emergence of cars, new transport planning places people and their movement in the center: it supports public transport, walking, and cycling and, at the same time, restrains car use [4]. As transportation substantially influences place-making, transport planners should also concentrate on the creation of more pleasant and sustainable environments 
and attractive places for people to live, work, shop, learn, and relax through removing obtrusive transport infrastructure and supporting other objectives, e.g., health. The SUMP is a well-structured document that reflects the needs of societal, economic, and technological changes in cities. (The SUMP concept evolved through more EU actions and policy steps. The momentum was given by the Thematic Strategy on the Urban Environment (see COM (2005) 718) which proposed the preparation of guidelines for Sustainable Urban Transport Plans. The common EU transport policy considers SUMPs an important planning document for making urban mobility more sustainable and cutting negative impact from transport, see the White Paper on Transport (2011) and the Urban Mobility Package (2013). A combination of measures should address emissions, urban congestion, and improved car alternatives (mainly public transport) and thus contribute also to the Green Deal goals and climate change mitigation. SUMPs are implemented under the principle of subsidiarity, in accord with national frameworks. They also have national titles like PDUs (Plans de Déplacements Urbains) in France, LTPs (Local Transport Plans) in the UK, or Plány udržitelné městské mobility in Czechia and function according to their local specifics.) Even though some traditional transport-related problems remain and even increase-namely, parking (with its space consumption, related traffic and emissions), poor air quality, traffic congestion and safety problems-new topics have appeared which require understanding and acceptance from policy makers and inhabitants (above all, climate change, increase in obesity, and population aging), see, e.g., [5] or [6]. Political goals play a considerable role, but they are confronted with the public voice (bottom-up initiatives), local limits, top-down motivations, and structured activities (such as national policy goals), as was demonstrated by Booth and Richardson [7]. Cities in the Central and Eastern European (CEE) countries are confronted even more with these changes, as they do not have a long tradition of integrated transport planning, bottom-up initiatives, and experience barriers connected with their institutional settings [8]. Furthermore, several bottlenecks are quite challenging for these cities because of insufficient previous experience with concepts such as multi-actor approaches and public involvement; although these activities constitute an important phase of SUMP preparation and implementation, they are often underestimated or even ignored by cities in practice, as is further demonstrated in this research.

This paper explores the institutional settings of and barriers to sustainable transport planning in cities of different sizes and how they reflect and implement the new planning paradigm in practice. By 2020, the first generation of SUMPs was developed by 40 Czech cities of various characteristics regarding their population size, geography, local GDP, and environmental and transport problems. We further investigate whether the cities with a SUMP benefit from it in comparison to those cities which do not have this strategic document in place. Our research is based on data collected during 45 structured interviews with key stakeholders in the field of sustainable urban mobility in Czechia and a questionnaire survey among other 76 representatives from 49 cities.

The paper is structured as follows: the next section focuses on the conceptualization of the transport planning paradigm and its change toward a new, more sustainable praxis; it also discusses the main factors influencing the implementation of this new planning paradigm in cities. Section 3 introduces the methodology used and describes the data collection process using structured interviews and an online questionnaire survey among key stakeholders influencing transport planning in cities. The results of our analyses are provided and discussed in Section 4 (main barriers to the sustainable mobility transition) and Section 5 (transport planning processes at the local level, new governance models in cities with respect to the transition, and differences between cities with and without a SUMP). The final section concludes.

\subsection{Defining the Transition to a Sustainable Transport Planning Paradigm}

There is a vast body of literature dealing with sustainable transport planning in cities, e.g., [9-12]. However, a unified way to tackle sustainability in urban mobility is 
missing, and common features of sustainable mobility are usually described instead of it. For example, using 30 studies conducted in North America and Europe, Marsden et al. [13] demonstrated that cities focusing on sustainable mobility share a strong degree of commonality of key strategy elements such as reducing the need to travel, reducing vehicle emissions, and improving public transport supply. Many triggers can further unify the approach and policymaking in cities, such as legislative measures (EU air quality standards, etc.) or technological changes (such as evolution of clean vehicles). The differences among cities consist in the level of emphasis, e.g., cities with historic cores are more focused on organizing and regulating deliveries to the central area.

In general, the difficulty in finding and agreeing on clear policy pathways toward sustainability lies in a real change and requires a "sophisticated policy mix" such as regulated pricing, location measures, and new business practices [14]. Another point is the implementation process, which is complicated by many parties and agendas but the users' response in terms of behavioral change is uncertain [15]. Altogether, these features make the policy and planning transition complicated and time-consuming, which is also confirmed by our study.

Sustainable mobility planning thus requires a complex approach; many researchers talk about a paradigm shift from conventional planning to new transport planning, e.g., [3,16-20]. These authors describe crucial differences between the two paradigms by using a complex set of factors: a stronger emphasis on accessibility instead of satisfying mobility; a street as a road becomes a street as space; the focus is shifted from motorized transport to all transport modes, often in a hierarchy with pedestrians and cyclists at the top and car users at the bottom; and reasonable travel times and travel time reliability replace the travel time minimization principle [16,21]. Banister [16] further argued that the tenet that "travel is a cost" and thus "travel times should be as short as possible" is not valid in the new transport paradigm as new technologies allow much greater travel time flexibility. A need for new policy actions that must be coordinated, and synergies found, such as transport and land-use measures $[17,18]$ working together for reduction of trip lengths is also urged [16]. Litman [19] investigated how sustainable transport planning objectives merge with those of public health policies, e.g., in the case of cycling with its potential to alleviate some health problems. He also referred to the fact that conventional transport policies often underestimate the additional crashes and emissions caused by more vehicle-driven kilometers and that the trip (length) reduction and more diversity in transport systems are desirable. The new paradigm is also based on an alignment of land use, environment, social issues, and transport policies as the key priorities in policy integration [12,22].

Litman and Burwell [23] represented another approach to the new transport planning paradigm: they stated that conventional planning assumes transport progress to be linear, consisting of newer, faster modes that displace older, slower modes (walking $\rightarrow$ bicycle $\rightarrow$ train $\rightarrow$ bus $\rightarrow$ automobile $\rightarrow$ improved automobiles); the older transport modes are not as important. On the contrary, the sustainable planning paradigm regards the progress of transport modes as parallel, each mode having its good potential, and it is aimed at creating balanced transport systems that use all modes and their interconnections. This does not assume that improved transport necessarily means faster travel or more mileage; improvements may increase comfort and safety, provide cost savings, or even reduce the total need for travel [23]. Santos et al. [24] defined three policy (sub)categories-physical policies (infrastructure planning), soft policies (mobility management, campaigning), and knowledge policies (research, expertise) — which represent a good "arsenal" for sustainable changes in the transport system and travel behavior.

\subsection{Factors Influencing Implementation of the New Transport Planning Paradigm}

The transport policy shift is generally characterized as being slow over long periods [25], which is caused by a lot of factors, above all the fixed nature of transport infrastructure in space and the long planning horizons of major investments, slow changes 
in politicians' and inhabitants' attitudes and behavior [15,26]. A bulk of research has focused on a better understanding of the constraints and drivers of sustainable urban mobility planning, such as the role of institutions, legislation, finances, acceptance and knowledge; see, e.g., [27-29]. Brůhová Foltýnová and Jordová [30] focused on the policy environment of cities and argued that its quality influences the implementation process of sustainable mobility measures, although the effect is not fatal and usually does not prevent the measure implementation. Still, some topics are not covered sufficiently; based on a review of 100 scientific papers, Marsden and Reardon [31] called for more research into transport policy governance and topics such as context, politics, power, resources, or legitimacy.

Emberger and May [32] reviewed papers on national transport planning frameworks and how sustainability was progressively included in geographically and culturally distant countries and argued that, regardless of historical and planning differences, each of them faces difficulties in setting up targets and selecting policy measures for sustainability in transport. The shift of focus from infrastructure provision to a multimodal approach and proper monitoring of objectives is a specific challenge for all of them. May et al. [33] reported that, in practice, the $28 \mathrm{EU}$ national governments differ considerably in how they supply conditions for the development of SUMPs and completely fail to do so in some cases. The CEE countries, which have just started adopting the new paradigm of sustainable transport planning, struggle with similar barriers.

Another important factor is a missing national policy framework for urban travel that would support and integrate policies on land use, health, and the environment and maintain consistencies in local policymaking.

A substantial part of the research focuses on Information and Communication Technologies/Intelligent Transport Systems (ICT/ITS) development, the concept of smart cities in the new transport mobility paradigm, see, e.g., [34-38]. The Internet and information technologies play an important role as they allow a mobility increase without the physical movement of people through a rise in collaborative or shared economy, allowing the environmental burden from transport and automated and individualized mobility to decrease, which might influence the shape of travel substantially. Autonomous mobility is expected to significantly change mobility and new business models for transport services. Autonomous vehicles will probably be part of normal traffic in most countries within a few years [39]. On the contrary, there is still limited empirical evidence on issues such as demand-responsive micro-transit (either taxi or bus-based), bike sharing, or mobility as a service and the role of autonomous mobility in their further development.

Safety and security also strongly influence user choice of travel mode, in particular, in railway and local public transport [40-42]. Safety from traffic collisions and personal security from crime are also crucial for users when deciding on cycling and walking, e.g., traffic calming and other safety measures are positively associated with both non-motorized transports [43]. On the other hand, a lack of personal security is negatively associated with walking. Both factors also influence the choice of destination.

The main principle of the new transport planning is to change citizen perception and travel behavior. Hurtado [44] spoke about five factors (five A's): accessibility, affordability, attractiveness, availability of sustainable options, and people's awareness of their existence, which have a considerable potential to change citizens' travel habits in the long term and should thus be considered and integrated into urban sustainability strategies.

An important factor in the successful implementation of sustainable mobility in cities is broad and active public support, including the introduction of proper communication between transport experts and the public to establish its support. In an ideal situation, citizens are not "objects" of mobility changes but rather active partners in sustainable solutions [16]. It is important to assess how transport systems are perceived by dominant actors and how politicians negotiate the process of motorization in concerned cities [45]. Hall and Sussman [46] pointed out that the use of the transport system by customers will play an important, if not vital, role in reaching the sustainable development. The approach 
"sustainable cities = sustainable people" is a simply formulated principle, but it is not easy to execute in practice. The political objective of creating more sustainable cities should be translated into plans and strategies focusing on the people and creating the environment for more sustainable behavior and lifestyles [44].

The new paradigm also sticks to new evaluation methods and more sustainable indicators. Cost-Benefit Analysis (CBA) is generally used and especially accepted to evaluate transport infrastructure projects (for European Union (EU) member states, CBA is required for funding from the Instrument for Pre-Accession countries, Cohesion Fund, or Structural Funds [47]) but it has been also criticized from various perspectives regarding its process, how it monetizes non-market goods, missing accounting for equity, the openness of the interpretation of its results, its ethics, and its discounting of long-term environmental consequences [47]. May et al. [33] made a general recommendation for national policies to establish support for monitoring and evaluation throughout the SUMP cycle. Recently, the European Commission developed a comprehensive set of indicators called SUMI to evaluate cities' mobility systems and to measure improvements that result from new mobility practices or policies (Sustainable Urban Mobility Iindicators (SUMI). Available online: https:/ / ec.europa.eu/transport/themes/urban/urban_mobility/sumi_en (accessed on 15 May 2021).

\section{Materials and Methods}

\subsection{Methodology Overview and State of the Art of SUMP Preparation in Czech Cities}

Following the European funding rules, cities of over 50 thousand inhabitants in Czechia had to prepare Sustainable Urban Mobility Plans (SUMPs) or so-called Sustainable Urban Mobility Frameworks (SUMFs) as their main strategic transport documents by 2019. SUMFs could have been prepared temporarily instead of SUMPs (until 2020). This exception, arranged with the European Commission (EC), gave Czech cities a more sustainable direction in the present transport planning and more time to allocate funding and prepare a strategic plan of the highest quality possible.

At the end of 2020, there were 40 SUMPs /SUMFs prepared by Czech cities. All 18 cities above 50 thousand inhabitants and other 8 cities above 40 thousand inhabitants have prepared their first SUMPs/SUMFs. Interestingly, other 14 smaller cities decided to prepare such a document voluntarily; their motivation was to solve their transport problems strategically by following the SUMP principles as principles of modern transport planning. The number of developed SUMPs suggests that cities are interested in the new comprehensive transport planning and understand the necessity of a change in the planning paradigm. However, is a shift toward sustainable transport planning happening, or are the SUMPs only strategies on paper? Do the cities with a SUMP apply more sustainable mobility planning principles than those without a SUMP?

To answer these questions, we chose a mixed-method approach. After a literature review, we identified relevant theoretical concepts and developed a methodology for the data collection and analyses. Then we conducted a qualitative survey among key stakeholders in the field of sustainable urban mobility (Section 2.2). Findings from this phase were discussed with the interviewees at a special workshop and further used to formulate research questions and to develop an electronic questionnaire, which was distributed to the largest Czech cities to obtain the opinions of the cities' representatives on the local praxis regarding strategic planning, public involvement, selection of transport measures and their ex-ante and ex-post evaluation (Section 2.3).

\subsection{Data Collection-Structured Interviews with Key Stakeholders}

The first phase of our research focused on identification of the main stakeholders in sustainable urban mobility. Freeman [48] defined stakeholders as those who can influence or be influenced by a decision, which, in turn, is a very broad concept: in the context of transport policy, all citizens of the city are directly affected by its form and anyone else is indirectly influenced due to the global impacts of fossil fuel use. The broad range of 
stakeholders relevant for transport planning has also been framed by other researchers and EU project teams [49-51]. In our research, we structured the stakeholders based on these findings and understood relevant actors/stakeholders as those who can directly influence decisions concerning transport policy at the city level from their job position. Following the methodology of [52], we considered stakeholders in the whole decisionmaking process and their abilities to influence the relevant decision-making processes. The identified actors included experts from various institutions influencing urban mobility: local politicians from ruling parties as well as from the opposition, top employees of municipal authorities (from departments of spatial development, transport, environment, etc.) and representatives of transport companies, also researchers, employees of relevant ministries, employees from the private sphere (especially companies offering new urban mobility services), and employees of non-governmental, non-profit organizations and journalists active in the given area. The relevant respondents were identified using a group of experts, who selected the main representatives from all the fields, and a snowball approach, where the respondents were asked to recommend other key actors.

We identified 83 relevant stakeholders from all the categories and invited them to an interview. Some of them refused, were not able to participate in our research, or suggested another relevant expert; they were replaced with similar respondents. We also identified further respondents, and by using a snowball technique we finally conducted 45 structured interviews between July and November 2018 (see Table 1).

Table 1. Structure of respondents by their position.

\begin{tabular}{lc}
\hline Local politician & 11 \\
\hline Representative of a municipality & 11 \\
\hline Representative of a transportation company owned by a municipality & 3 \\
\hline Representative of a ministry & 4 \\
\hline Consultant, transportation expert, researcher & 5 \\
\hline Representative of an NGO & 4 \\
\hline Representative of a private company providing mobility services & 6 \\
\hline Journalist & 1 \\
\hline Total & 45 \\
\hline
\end{tabular}

Source: Own survey.

In terms of basic sociodemographic characteristics, men prevailed in the sample of key stakeholders; most of the respondents had a university education and a relatively long practice in the transport sector (14 years) as well as in their current job position (8 years on average).

A significant part of the interviews was conducted with respondents who had a relation to Prague, either as a politician or a senior employee of the city hall or as an inhabitant and person working in Prague (researchers, NGO employees, representatives of private companies, etc.). Representatives of ministries whom we approached were interviewed not about a specific city but about the situation in Czech cities in general.

Each interview was divided into five parts. First, the respondents were introduced to the research objective and process. Then the respondents explained how they could influence the decision-making processes regarding sustainable mobility planning in their city or in cities whose transport policy they could affect, and how satisfied they were with the existing praxis. The second part further focused on the main transport problems in the cities and the main stakeholders, including the respondents' main opinion proponents and opponents. The next part of the interview dealt with the respondents' expectations and wishes regarding long-term urban mobility development, and they were asked to formulate an ideal vision of sustainable mobility for their city. Respondents were also asked to evaluate 42 statements regarding further development of urban mobility (this part of the 
survey was analyzed using the Q-methodology; the analysis and its results were described in [8]). The fourth part focused on recognition of the main barriers to sustainable mobility measures throughout the planning cycle (i.e., planning and preparation of measures, implementation of measures, and their evaluation when implemented). The final part recorded some basic data about the respondents and the interview progress (education, gender, age, job position, interview duration). One interview took $46 \mathrm{~min}$ on average.

\subsection{Data Collection-Questionnaire Survey}

Some results of the interviews were used for the preparation of an online questionnaire. The questionnaire was addressed to heads of relevant departments of Czech municipal authorities (departments of transport, spatial planning, strategic planning, or the environment) and/or political representatives responsible for transport development. We approached them directly by email (380 email addresses in total); furthermore, two local networks of cities were used to distribute information about our research and a link to the questionnaire for their members (other 80 email addresses). The data collection took place between January and February 2019. We received 76 correctly completed questionnaires in total from 49 cities, while we managed to cover equally all sizes of cities: one fifth of the cities were above 100,000 inhabitants, the same number of cities were sized between 50,000 and 100,000 inhabitants, $24 \%$ belonged to the size category of 30,000 to 50,000 inhabitants, $28 \%$ were between 10,000 and 30,000 inhabitants, and 9\% of the cities had fewer than 10,000 inhabitants. The cities in our survey had different geographical and demographical conditions and challenges, socioeconomic profiles, and environmental and transport problems. The questionnaires were anonymized to encourage respondents to answer the questions openly, but respondents could provide their emails. The only identification factor was the size of the city they represented.

The questionnaire focused on the following research areas: (i) transport problems in cities; (ii) implementation of innovative transport measures and experience with them; (iii) decision-making processes in the transport field; and (iv) praxis in the evaluation of transport-related policies and strategies. The main categories of transport problems were defined based on the results of the qualitative part-interviews with stakeholders. The questionnaire served as verification of the results among a wider range of cities and their representatives. Sustainable mobility measures included in the questionnaire were chosen based on the literature review-those that were typically connected with the new transport planning praxis. The decision-making processes and governance models included in the research covered the setting of (quantifiable) targets, selection of policy measures, integration of sector policies, including the concept of smart cities, communication and public involvement, and evaluation and monitoring of measures and policies. We further analyzed statistically significant differences between cities with and without a SUMP using two-sample $t$-tests, where the tested variable was put in relation to the yes/no binary variable, which described whether a city had a SUMP available or not.

\section{Institutional Settings for the Sustainable Mobility Paradigm Change}

A qualitative analysis of interviews with the stakeholders provided us with a picture of the praxis in transport planning, the roles of different stakeholders in the whole process and the main barriers to further transition toward sustainable mobility in Czech cities. We focused on identification of the main barriers to sustainable mobility planning during the three phases of the planning cycle: planning, implementation, and evaluation.

In the phase of planning and preparation of mobility policies and measures, several types of perceived barriers were found. Above all, it was a lack of communication between key actors involved in the preparatory phase (local governments, relevant institutions, the non-profit sector, and citizens). There was usually a low level of trust and agreement among these actors (i.e., the actors' perceptions of finding a solution and implementing a suitable measure differed significantly), and this was associated with subsequent intentional and unintentional delays in projects. The negotiation and approval process, including 
finding a political agreement, was extremely difficult. This was further exacerbated by a four-year election cycle, which was often not long enough to take all the necessary steps in the preparatory phase. There were numerous cases of ongoing projects stopped by a new city-level political representation after the elections. According to the respondents, the qualification preconditions of human resources in individual institutions (especially in public administration) were also very diverse. Beside barriers resulting from disparate communication, the ideological and qualification aspects of individual legislative barriers existed. In this case, it was mainly a lengthy zoning and construction procedure, which complicated the process of planning large-scale measures in the field of urban transport.

In the project implementation phase, legislative barriers (such as the Public Procurement Act, influencing the price of tenders and the quality of the offered solutions) were mentioned the most often by our respondents. The second most common barrier concerned obstacles while purchasing land for transport infrastructures. There were cases of deliberate purchase of land by a third party, which subsequently caused a delay or the total impossibility of the investment. Even in the implementation phase, persistent problems in communication among stakeholders were often evident. Different ideas, opinions, and limited will to find agreement also caused significant extensions to the implementation phase. In general, the phase of measure implementation was limited mainly by procedural and formal length (partly affected by legislation), limited communication, and the associated deliberate obstruction of institutions or individuals.

The final phase of evaluation - was found to be the most problematic. There was a consensus among the respondents that ex-post evaluation was not used systematically by Czech cities. Following the introduction and implementation of transport measures, ex-post evaluations often did not take place for objective reasons, such as a lack of suitable data or funding for quality evaluation. However, the reasons were also completely pragmatic and tendentious. Stakeholders agreed that there was often no will or interest to retrospectively evaluate newly introduced measures and deal with evaluation results. Also, it turned out that there were not enough qualified companies or experts on the market who could carry out high-quality evaluations correctly and objectively. The ex-post evaluation thus took place with the level of elementary indicators that were publicly available (e.g., data on traffic intensity counts in cities, public transport volumes and performance-if they were handed over by providers). The interviewees were also unanimous in that the evaluation culture associated with public funding was not developed in Czechia.

The main identified barriers were then verified during the questionnaire survey. Its results confirmed that the main barriers to sustainable transport planning in cities related to the institutional and economic structure of the society-above all, a lack of funds, complicated processes connected with planning and execution of transport policies, complicated legislation, a lack of political consensus and attitudes of the society, which were divided into groups friendly and opposed to cars in cities. These findings were in line with the literature. Bosetti et al. [28] revealed financial, legislative, technological, political, and institutional barriers during the analysis of CIVITAS Plus cities implementing sustainable mobility measures. Technological and institutional barriers were stressed by Farla et al. [27] and Lah [29] as blocking the transition toward sustainable mobility. On the contrary, the respondents in our survey did not perceive non-existent or undeveloped technology as a really serious problem. See Table 2 for more details. 
Table 2. Evaluation of the seriousness of barriers to sustainable mobility.

\begin{tabular}{lr}
\hline Barriers & Seriousness \\
\hline Lack of funds & 3.53 \\
Long legislation and planning processes & 3.49 \\
Attitudes of the society & 3.47 \\
Legislation & 3.29 \\
Acceptability & 3.08 \\
Lack of political consensus & 2.86 \\
Lack of human resources & 2.86 \\
Lack of communication & 2.82 \\
Dysfunctional institutions & 2.59 \\
Unavailable technology & 2.24 \\
\hline
\end{tabular}

Note: The respondents evaluated the barriers on a scale from 1 to 5 according to how much specific barriers obstruct sustainable mobility in cities; $1=$ least serious, $5=$ most serious barrier; the numbers are averages of their answers.

Furthermore, the respondents were asked a set of questions focused on decisionmaking processes and the roles of different stakeholders in the whole process. The answers were quite diverse, and it seems that there was no common view and reflection of these processes among the different stakeholders. Respondents from the national authorities identified mayors and deputy mayors responsible for transport and the city council (politicians) as the most important drivers because they could usually directly influence the decisions. These respondents saw the top-down approach as functional and stated that politicians' willingness and interest could motivate the public and institutions in the city. However, this outward view was not shared by the rest of the respondents (officials from transport departments, NGOs, transport specialists), who emphasized that the political representatives stayed in their positions for a short-term compared to planning horizons and could even hinder some sustainable measures due to their priorities and a lack of internal consensus. This is not specific only to Czech conditions; similar findings were made by Forrester [18] for UK local authorities. On the contrary, Czech cities emphasize the role of municipal organizations and companies, such as municipal public transport operators or coordinators and technical departments with planning competencies in transport. The governance is in the hands of elected politicians who use results and data provided by technical departments. In the technical and organizational senses, they have great influence, and there is the risk of an exclusive technocratic approach. At the same time, several stakeholders mentioned that the academic and research fields should be exploited more for building transport solutions in cities, such as land-use tools for the regulation of car mobility, especially polycentric models and the concept of compact cities. The knowledge required for a transition to the sustainable mobility paradigm is available, but researchers should be involved more frequently in the decision-making processes, so that they can contribute research findings on topical sustainable solutions and bring back evidence for their follow-up research.

Attention should also be paid to traffic generators, such as large employers and zones attracting a lot of daily trips, and to parking policy, which can be used effectively to manage mobility volumes in (central) parts of cities. Vehicle producers, energy and technology providers, ICT companies and experts enter the process naturally, as they supply technologies for smart mobility projects, as often mentioned by our respondents.

In general, sustainable mobility had its individual proponents at different levels and across different organizations in Czech cities. A more frequent involvement of stakeholders from different backgrounds and institutions can be perceived as the first step of the transition toward the new mobility planning paradigm. Furthermore, most of the stakeholders saw the transition toward sustainable mobility as beneficial for cities and society. 


\section{Results}

\subsection{Main Transport Problems in Cities}

Each city is unique and requires an individualized approach to its transport problems. However, there is a substantial number of common transport-related problems that challenge most cities. Their solutions can then be shared among cities as inspiration to each other. We identified systematic features predicting transport problems in cities.

Based on the interviews with the key stakeholders and a subsequent verification via the questionnaire survey, the main existing transport problems in the urban areas include parking (53\% of the cities indicated it as serious or very serious), lack of funds (35\%), traffic congestion and through traffic (both 34\%), high intensity and lack of regulation of car traffic (31\%), and unregulated freight transport (28\%). Figure 1 shows the seriousness of the transport-related problems and the size of the city; it reveals that there might be a relationship between the city size and the relative seriousness of some transport problems. For example, parking or missing car traffic regulation seem to be more serious problems in larger cities than in smaller ones. On the contrary, smaller cities complained more about through traffic, but also about problems connected with the high intensity of motorized traffic and traffic congestion, especially in peak hours. However, these findings were not statistically significant (the Chi-squared test did not reject the hypothesis that the city size and seriousness of the problems are independent); similarly, we did not reject the hypothesis that the existence of a SUMP and the seriousness of the transport-related problems are independent; the only exception was the problems connected with not providing inhabitants with sufficient information about the state and impacts of transport (Chi-squared $=28.59, \mathrm{df}=16, p$-value $=0.027)$.

\subsection{Experience with Sustainable Mobility Measures}

We further focused on the cities' experiences with sustainable mobility measures. First, we identified the cities that have implemented particular measures during the last 20 years; those that implemented a certain measure were asked whether they would recommend it to other cities based on their own experience or not. Figure 2 summarizes the main results.

Most of the cities in our sample have implemented measures focused on transport infrastructure and public space improvements, such as traffic calming measures, walking and cycling infrastructure completion, enhancement of public transport services (better comfort at stops and in vehicles, information technology measures, etc.). The satisfaction of cities with these measures is quite high. Measures connected with regulation of motorized traffic or quite expensive infrastructural projects have been implemented in fewer cities and more respondents did not recommend them or did not know if they were recommendable. Surprisingly the least popular, with the highest share of "not recommended" answers were measures on electromobility, construction of multimodal terminals, personalized trip planning (at a mobility center), car sharing and bike sharing. The most likely reasons were: a relatively short time elapsed from their implementation and higher initial investments.

The data also show that there is a relationship between the city size and the satisfaction with certain measures. This was confirmed statistically (using the Chi-squared test); see Table 3 .

\subsection{Praxis of Cities Regarding Policy Integration, Monitoring, Evaluation, and Involvement of Stakeholders}

The sustainable transport planning paradigm emphasizes specific governance models such as the integration of various (sectoral) policies and strategies, regular data monitoring and evaluation, and involvement of stakeholders. We tried to find out the common praxis of cities in these fields.

Most of the 49 analyzed cities (with an exception of seven small cities) have developed their long-term city strategy, which naturally includes transport. The new transport strategic document-either a SUMP or a SUMF-has been completed or is in preparation in 17 cities and 5 cities, respectively, from our sample (which means altogether $45 \%$ of 
the analyzed cities) and additionally, $29 \%$ of the analyzed cities have also developed their Smart City strategy. Traditionally, Czech cities are used to making Transport Development Plans; $43 \%$ of cities from our survey had such a plan for motorized traffic at disposal, while only two cities (4\%) reported that they had a Cycling Development Plan and none of them reported the existence of a Walking Development Plan.
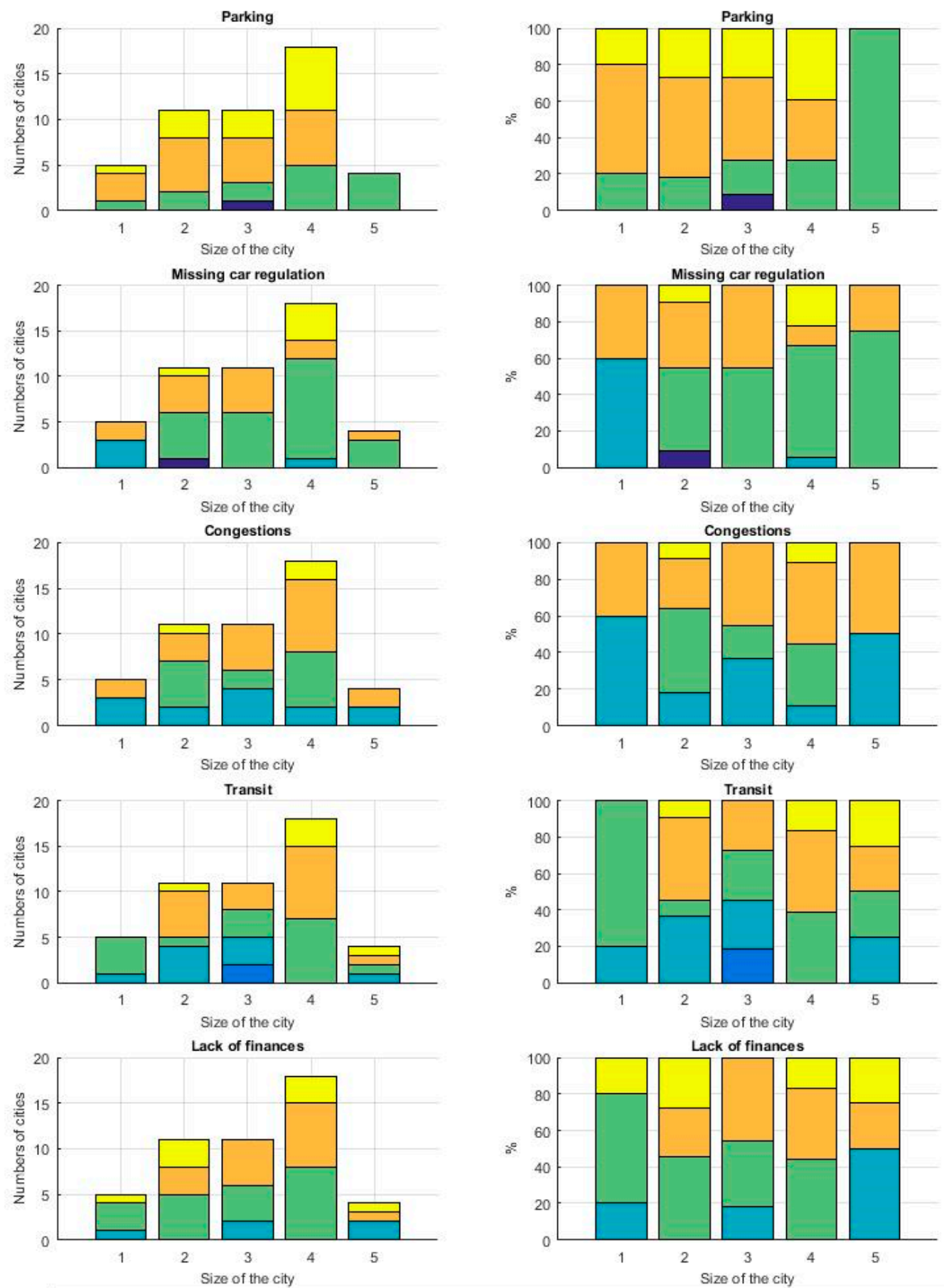

I dont know

No problem Little problem

Medium problem

Serious problem

Very serious problem

Figure 1. Main transport problems in relation to the city size. Source: Own survey. Note: City size: $1=$ more than 100,000 inhabitants; $2=50,000-100,000$ inhabitants; $3=30,000-50,000$ inhabitants; $4=10,000-30,000$ inhabitants; $5=$ under 10,000 inhabitants. 


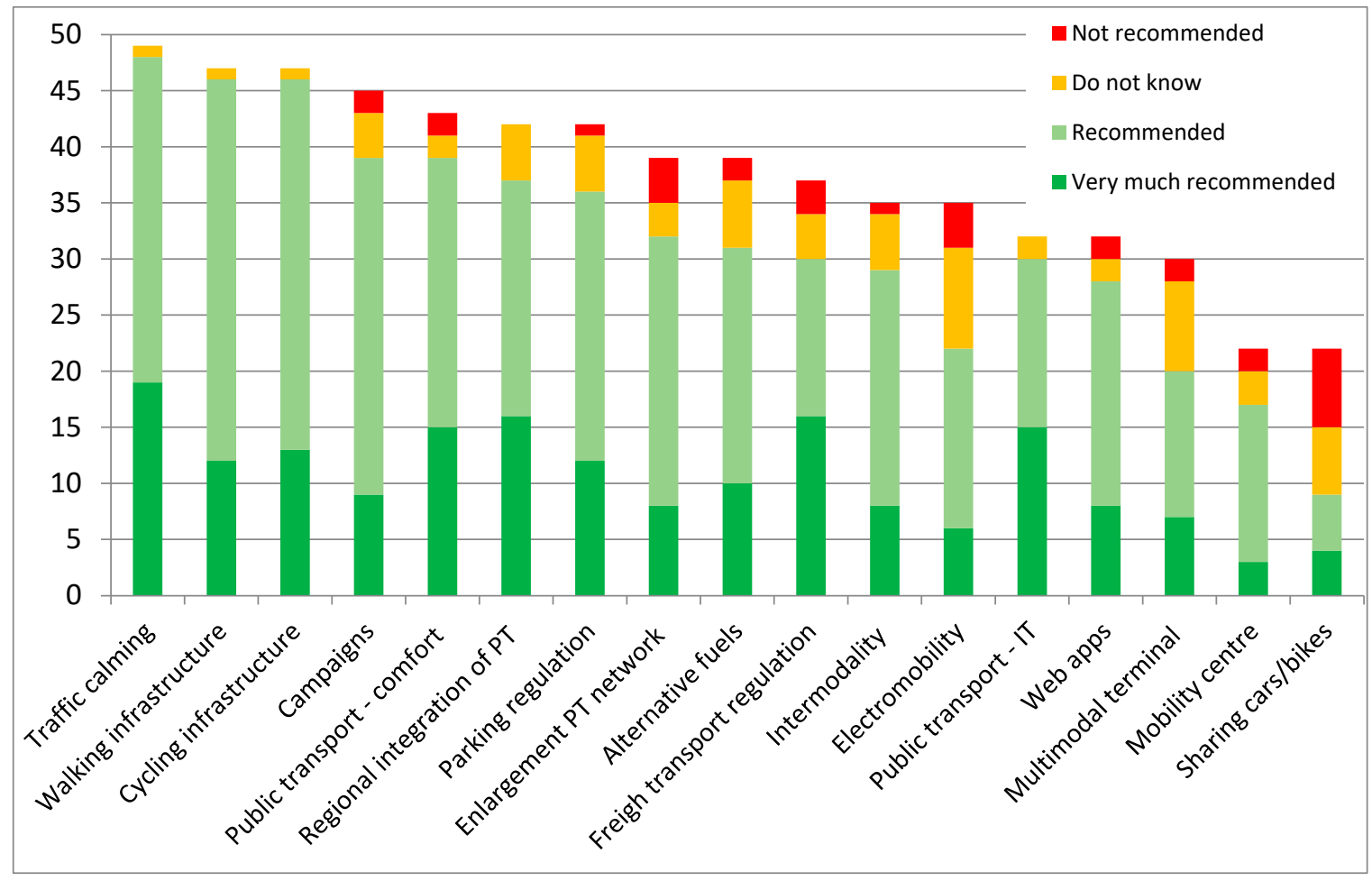

Figure 2. Experience of Czech cities with sustainable mobility measures (answers of cities that have implemented such a measure in the last 20 years). Source: Own survey.

Table 3. City size and satisfaction with implemented measures (using Chi-squared tests).

\begin{tabular}{ccc}
\hline Measure & Chi-Squared & $p$-Value \\
\hline Multimodal terminal & 23.624 & 0.02287 \\
PT support_IT (digital panels, smart check-in, green wave for PT, etc.) & 30.234 & 0.01683 \\
PT_increase in comfort at PT stops and vehicles & 23.557 & 0.02335 \\
PT—enlargement of the network & 21.467 & 0.04395 \\
Integration of PT within a region & 25.769 & 0.01157 \\
Support for alternative fuels in PT and city vehicle fleet & 25.445 & 0.06236 \\
Intermodality (connection of P + R with PT, bicycle lanes with stations, etc.) & 22.766 & 0.02978 \\
Parking regulation & 28.885 & 0.02472 \\
Campaigns (to support cycling, PT, safe routes to schools, etc.) & 18.538 & 0.06631 \\
Trip planning & & 0.1003 \\
\hline
\end{tabular}

Source: Own calculation.

Only $31 \%$ of the analyzed cities reported that they regularly evaluated their strategies on paper; if so, they mostly evaluated action plans for the respective strategy on a 5-year or even a yearly basis.

The evaluation process requires high-quality data. Therefore, we asked further about which transport-related data were regularly collected by cities and which indicators were monitored. It turned out that cities do not pay much attention to the collection of transportrelated data, the regularly collected data that cities evaluate are mostly those provided by external institutions, such as data about public transport (PT) operation, costs and revenues, passenger numbers (mostly collected by (PT) operators), data on traffic accidents (usually collected by the police) or emission levels (measured by the Czech Hydrometeorological Institute or the National Institute of Public Health, and only partially by municipalities themselves).

The paradigm shift toward sustainable mobility planning in cities is also closely connected with stakeholders' involvement. In Czechia, public involvement is a relatively new 
concept that cities should embrace more widely; our data indicated that this process was quite slow. The communication strategy of Czech cities is quite passive, based mostly on a one-way information flow (using websites, emails, SMS), the involvement of experts (specialized working groups, thematic commissions, etc.) and public consultations prescribed by legislation for land use planning and large infrastructure projects. Our data also showed that cities are quite often confronted with petitions and other complaints raised by citizens about planned or implemented transport measures. Active communication and campaigning organized by cities are still not common and in many cases, they are initiated by external organizations, mostly NGOs (such as campaigns and actions under the European Mobility Week coordinated by the Ministry of the Environment).

\subsection{Differences between Cities with and without a SUMP}

Based on the data from our survey among cities, we further tried to answer the question of whether the cities with the SUMP benefit from it in comparison to those cities that do not have this strategic document in place. Using $t$-tests, we compared data from cities with a SUMP with those that have not developed such a strategy. The results are summarized in Table 4.

Table 4. Differences between cities with and without a SUMP using $t$-tests.

\begin{tabular}{|c|c|c|c|}
\hline & Cities without a SUMP & Cities with a SUMP & $t$-Test ( $p$-Value) \\
\hline City size & Average category 2.3 & Average category 3.8 & 0.000 \\
\hline \multicolumn{4}{|c|}{ Transport problems } \\
\hline Road accidents & 2.36 & 2.69 & 0.058 \\
\hline Missing information & 2.57 & 3.09 & 0.060 \\
\hline Missing funds & 3.68 & 3.28 & 0.100 \\
\hline \multicolumn{4}{|c|}{ Experience with transport measures (is the measure recommendable to other cities) } \\
\hline Terminal & 0.11 & 0.75 & 0.0002 \\
\hline PT & 0.46 & 1.17 & 0.001 \\
\hline PT comfort & 0.85 & 1.42 & 0.004 \\
\hline PT network & 0.50 & 1.08 & 0.006 \\
\hline Integration & 0.89 & 1.25 & 0.071 \\
\hline Electromobility & 0.25 & 0.69 & 0.044 \\
\hline $\begin{array}{c}\text { Promotion, PR, } \\
\text { campaigns }\end{array}$ & 0.43 & 0.97 & 0.004 \\
\hline $\begin{array}{l}\text { Web pages and } \\
\text { applications }\end{array}$ & 0.36 & 0.92 & 0.005 \\
\hline \multicolumn{4}{|c|}{ Implementation of transport measures } \\
\hline PT & 0.39 & 0.89 & 0.000 \\
\hline PT comfort & 0.78 & 1.00 & 0.010 \\
\hline Fuels & 0.64 & 0.92 & 0.010 \\
\hline Electromobility & 0.54 & 0.86 & 0.006 \\
\hline Promotion & 0.57 & 0.81 & 0.050 \\
\hline Parking & 0.71 & 1.00 & 0.003 \\
\hline Sharing & 0.21 & 0.75 & 0.000 \\
\hline \multicolumn{4}{|c|}{ Transport planning practice } \\
\hline Transport model & 0.54 & 0.86 & 0.076 \\
\hline Participation & 5.33 & 6.71 & 0.005 \\
\hline Data analysis & 0.14 & 0.86 & 0.003 \\
\hline Data collection & 2.08 & 4.06 & 0.000 \\
\hline
\end{tabular}

Source: Own calculation.

Not surprisingly, the cities with a SUMP are larger on average than those without a SUMP. The reason is that the largest cities above 50 thousand inhabitants are required to make this plan if they apply for funding. However, we had other 17 smaller cities with a SUMP in our sample. When focusing on the transport problems that cities face, our analysis suggests that representatives of cities with a SUMP perceived fewer problems 
with financing transport measures, but more often mentioned problems with accidents; they are also more ambitious regarding communicating the messages and involvement of citizens in transport planning.

When we looked at the transport measures implemented by the cities, representatives of the cities with a SUMP had a better experience on average with sustainable transport measures. The respondents were asked if they had implemented a particular measure and if so, if they would recommend it to other cities using a scale from +2 (strongly recommended) to -2 (strongly NOT recommended). Therefore, only cities having practical experience with the measure were involved in this analysis. The cities with a SUMP have implemented more sustainable mobility measures on average (it is probably also because they are larger on average). Regarding experience with them, the difference was notably in favor of better experience for cities with a SUMP - especially for measures such as building new multimodal terminals ( 0.75 for cities with a SUMP and 0.11 for cities without a SUMP), improving PT services (1.17 versus 0.46$)$, particularly PT comfort and network enhancement, improving intermodality ( 1.25 versus 0.89 ) and support to electromobility ( 0.69 versus 0.25$)$. A statistically significant difference was also apparent for communication measures such as information campaigns ( 0.97 versus 0.43 ) and specialized web and mobile applications (0.92 versus 0.36 ).

Our analysis revealed that cities with a SUMP used a transport model in the planning process more often ( 0.86 versus 0.54 on a scale from 0 to 1 ), create more public participation activities (6.71 versus 5.33 when calculating the number of different activities to involve stakeholders and the public in transport-related decision-making), collect substantially more data ( 0.86 versus 0.14 on a scale from 0 to 1$)$, and make more analyses to support planning and decision-making (4.06 versus 2.08 when measuring how many data categories were regularly monitored and collected by the city itself).

Regarding perceived barriers, there was surprisingly no statistically significant difference between these two groups of cities: both groups struggled with similar obstacles.

It should be emphasized that the data were collected in the period when cities were elaborating or completing their first SUMPs/SUMFs. Hence, these strategies were not fully effectuated yet. SUMPs/SUMFs of Czech cities are still brand new and have just started. Our research then referred to the first phase; more research and SUMP evaluation over a longer time span is needed to reflect and analyze the implementation process and impacts of selected measures on practice.

\section{Discussion}

The paper focuses on changes in conventional transport planning and investigates the new paradigm setting sustainability of transport and protection of the urban environment as the utmost strategic goals among Czech cities. The literature gives us a full picture of the trend of such paradigm changes. The notion of "Sustainable Transport" is manyfold, embracing alternative modes to car use, smart solutions, safety and security measures, and other elements making the transport system more effective and less polluting. There is also a long-term tendency to unify sustainable transport policies, represented by the EU concept of Sustainable Urban Mobility Plans. These became the cornerstone of our research when we looked into their application within the EU and examined the transport planning process in Czech cities.

We used both qualitative and quantitative data collected through interviews and a questionnaire survey among 45 key stakeholders influencing transport planning in Czech cities between June 2018 and February 2019. Our research indicates that most of the interviewed representatives of cities feel the necessity to tackle improvement of public transport, cycling, and walking factors, which make up essential parts of sustainable transport planning. There are progressive cities and at the same time cities that hesitate at radical regulation of car transport (such as reduction of parking spaces, regulation of car traffic in inner urban zones, or larger prioritizing of public transport and non-motorized 
modes) even though they suffer from traffic congestion and urban space consumption. It is becoming clear that such changes are inevitable and should be applied soon.

Within our research, we also investigated the main barriers to sustainable mobility. They are linked to complicated legislation, lack of political consensus, and contradictory or weak attitudes of society, which has traditionally been rather car-oriented. The scientific literature revealed also the institutional, financial, or technical barriers, such as a lack of skills or even a rigid political system that does not allow for more radical changes [17]. Emberger [53] stated that the transition to sustainability in transport can be complicated by the historically car-oriented urban planning and subsequent difficulties in changing travel habits. This may explain also some of our findings in Czech cities, like complications in reaching political consensus or hesitation and obstacles to applying more car-restrictive measures. Hesitant political commitment to the principles of sustainability and adequate solutions were argued also by May et al. [33], based on an extensive review of the EC and European Council of Ministers of Transport (ECMT) works and national studies.

Furthermore, we realized that in the analyzed cities, some of the main features and key success factors of SUMPs-systematic and efficient involvement of relevant stakeholders, including public consultations, and monitoring and evaluation of transport measures and policies - are practiced at a low level. The perception of a need for regulatory measures resulting in a significant transport behavior change and subsequent redistribution of modal shares was quite low among local politicians.

Some triggers help sustainable transport planning, such as financing of SUMP/SUMF development from the EU/national level, legislative standards for air quality, or subsidies for implementation of new technologies, e.g., clean vehicles (especially renewal of PT fleets). However, our survey indicates that there are Europe-wide recommended "sustainable measures" which are not much deployed in analyzed Czech cities (yet), such as shared mobility (car sharing, bike sharing, or car-pooling platforms), electromobility (most probably due to market conditions and the necessity to establish accompanying infrastructure), and, surprisingly, also mobility advice (mobility centers). The cities also do not have much experience with shaping mobility behavior and positively influencing user choices. It seems that at this "starting point," having a SUMP does not make a substantial difference regarding perceived barriers and transport problems that cities face at present. Nevertheless, we presume this will change soon when implementation of the SUMPs will bring the first effects.

However, our results further indicate that a SUMP brings substantial benefits to cities of all sizes, it helps their decision-making and policy planning, even in the initial phase of the sustainable mobility paradigm change. The cities that have SUMPs in place implement sustainable transport measures more often, use transport models in strategic decisions more often, create more participation activities, and are better at evaluation, especially monitoring and analyzing substantially more data regularly.

\section{Conclusions}

European cities face a policy paradigm shift in transport planning, which has been accelerated by the European policy encouraging cities to make so-called Sustainable Urban Mobility Plans. The planning concept is entirely new in many European countries, and it thus brings a lot of challenges to cities with no previous experience with this concept.

This paper explores the institutional issues regarding practice and barriers relating to this new sustainable transport planning paradigm in Czech cities of various sizes, geographical, economic and demographic conditions, environmental and transport problems.

Our research demonstrates that Czech cities can successfully apply the EU concept of Sustainable Urban Mobility Plans, and even smaller cities are interested in this concept. The findings show that SUMPs bring substantial benefits to cities of all sizes, even in the initial phase of their implementation. The cities that have developed a SUMP apply various sustainable transport measures more often, create more participation activities, 
and are better at evaluation than cities without a SUMP. We can thus confirm SUMPs will undoubtedly make a difference.

However, there are some limitations to our research. This study was undertaken in the institutional context of the Czech Republic. Therefore, the validity of some results applies mainly to countries with a similar historical development of city planning. These results also reflect only the first phase of SUMP development and the beginning of their implementation. More research is needed especially about the long-term impacts of SUMPs on the sustainability of cities.

Author Contributions: Both authors developed the theory, verified the analytical methods, discussed the results and contributed to the final manuscript. They have read and agreed to the published version of the manuscript. Conceptualization, R.J. and H.B.-F.; methodology, R.J. and H.B.-F.; investigation, R.J. and H.B.-F.; formal analysis, H.B.-F.; writing—original draft preparation, R.J. and H.B.-F.; writing-review and editing, R.J. and H.B.-F. Both authors have read and agreed to the published version of the manuscript.

Funding: This research was funded by the Technology Agency of the Czech Republic, grant number TL01000462.

Institutional Review Board Statement: Not applicable.

Informed Consent Statement: Not applicable.

Data Availability Statement: Not applicable.

Conflicts of Interest: The authors declare no conflict of interest.

\section{References}

1. COM/2019/640 Final. The European Green Deal. Communication from the Commission to the European Parliament, the Council, the European Economic and Social Committee of the Regions. Available online: https://eur-lex.europa.eu/legal-content/EN/TXT/ ?uri=COM\%3A2019\%3A640\%3AFIN (accessed on 23 April 2021).

2. Brůhová Foltýnová, H.; Attard, M.; Mělo, S. Topical collection on the role of planning towards sustainable urban mobility. Eur. Transp. Res. Rev. 2018, 10, 1-2. [CrossRef]

3. Rupprecht, S.; Brand, L.; Boehler-Baedecker, S.; Brunner, L.M.; Colclough, A.; Dragutescu, A.; Horvat, M.; Durlin, T.; Werland, S.; Rudolph, F. Guidelines for Developing and Implementing a Sustainable Urban Mobility Plan, 2nd ed.; Rupprecht Consult-Forschung \& Beratung GmbH: Weinheim, Germany, 2019.

4. Jones, P. The evolution of urban transport policy from car-based to people-based cities: Is this development path universally applicable? In Proceedings of the 14th World Conference on Transport Research, Shanghai, China, 10-15 July 2016; Available online: http: / / www.wctrs-conference.com (accessed on 6 January 2021).

5. COM (2020)789 Final. Sustainable and Smart Mobility Strategy-Putting European Transport on Track for the Future. Communication from the Commission to the European Parliament, the Council, the European Economic and Social Committee of the Regions. Available online: https:/ / eur-lex.europa.eu/legal-content/EN/TXT/HTML/?uri=CELEX:52020DC0789\&from=EN (accessed on 23 April 2021).

6. Baldwin Hess, D.; Kozlowski Russell, J. Influence of Built Environment and Transportation Access on Body Mass Index of Older Adults: Survey Results from Erie County, New York. Transp. Policy 2012, 20, 128-137. [CrossRef]

7. Booth, C.; Richardson, T. Placing the public in integrated transport planning. Transp. Policy 2001, 8, 141-149. [CrossRef]

8. Brůhová Foltýnová, H.; Vejchodská, E.; Rybová, K.; Květoň, V. Sustainable urban mobility: One definition, different stakeholders' opinions. Transp. Res. Part D 2020, 8, 102465. [CrossRef]

9. Henke, I.; Carteni, A.; Molitierno, C.; Errico, A. Decision-Making in the Transport Sector: A Sustainable Evaluation Method for Road Infrastructure. Sustainability 2020, 12, 764. [CrossRef]

10. Holden, E.; Banister, D.; Gössling, S.; Gilpin, G.; Linnerud, K. Grand Narratives for sustainable mobility: A conceptual review. Energy Res. Soc. Sci. 2020, 65, 101454. [CrossRef]

11. Gil, A.; Calado, H.; Bentz, J. Public participation in municipal transport planning processes-The case of the sustainable mobility plan of Ponta Delgada, Azores, Portugal. J. Transp. Geogr. 2011, 19, 1309-1319. [CrossRef]

12. Hull, A. Policy integration: What will it take to achieve more sustainable transport solutions in cities? Transp. Policy 2008, 15, 94-103. [CrossRef]

13. Marsden, G.; Trapenberg Frick, K.; May, A.D.; Deakin, E. How do cities approach policy innovation and policy learning? A study of 30 policies in Northern Europe and North America. Transp. Policy 2011, 18, 501-512. [CrossRef]

14. Eddington, R. The Eddington Transport Study. In Main Report: Transport's Role in Sustaining the UK's Productivity and Competitiveness; The Stationery Office: London, UK, 2006. 
15. Marsden, G.; Docherty, I. Insights on disruptions as opportunities for transport policy change. Transp. Res. Part A 2013, 51, 46-55. [CrossRef]

16. Banister, D. The sustainable mobility paradigm. Transp. Policy 2008, 15, 73-80. [CrossRef]

17. May, A. Sustainable urban transport policies: Facilitating effective decision-making. In Keynote Paper 4B, Session 4A: Urban Planning, Transport and Development Tensions; CODATU XIII: Ho Chi Minh City, Vietnam, 2008.

18. Forrester, J. Improved partnership working for local authority transport planning. Eur. J. Transp. Infrastruct. Res. 2009, 9, 314-330.

19. Litman, T. Transportation and Public Health. Annu. Rev. Public Health 2013, 34, 22. [CrossRef]

20. Sitányiová, D.; Masarovičová, S. Development status of sustainable urban mobility plans in European Union Member States. Int. J. Transp. Dev. Integr. 2017, 1, 16-27. [CrossRef]

21. Lyons, G.; Urry, J. Travel time use in the information age. Transp. Res. Part A 2005, 39, 257-276. [CrossRef]

22. Banister, D. Innovation in Mobility: Combining Vision, Technology and Behavioural Change. Dossiers: Innovation for Sustainable Development. 2014. Available online: http:/ / regardssurlaterre.com/en/innovation-mobility-combining-vision-technologyand-behavioural-change (accessed on 6 January 2021).

23. Litman, T.; Burwell, D. Issues in sustainable transportation. Int. J. Glob. Environ. Issues 2006, 6, 335-339. [CrossRef]

24. Santos, G.; Behrendt, H.; Teytelboym, A. Part II: Policy instruments for sustainable road transport. Res. Transp. Econ. 2010, 28, 46-91. [CrossRef]

25. Howlett, M.; Cashore, B. The dependent variable problem in the study of policy change: Understanding policy change as methodological problem. J. Comp. Policy Anal. Res. Pract. 2009, 11, 33-46. [CrossRef]

26. Docherty, I.; Shaw, J. The transformation of transport policy in Great Britain? “New Realism" and New Labour's decade of displacement activity. Environ. Plan. Part A. 2011, 43, 224-251. [CrossRef]

27. Farla, J.; Alkemade, F.; Suurs, R.A.A. Analysis of barriers in the transition toward sustainable mobility in the Netherlands. Technol. Forecast. Soc. Chang. 2010, 77, 1260-1269. [CrossRef]

28. Bosetti, S.; Di Bartolo, C.; Malgieri, P.; Sitran, A.; Brůhová-Foltýnová, H.; Jordová, R.; Kurfürst, P.; Smutková, D. Policy Recommendations for EU Sustainable Mobility Concepts Based on CIVITAS Experience; CDV: Brno, Czech Republic, 2014.

29. Lah, O.; Lah, B. Sustainable Urban Mobility Pathways_Policies, Institutions and Coalitions for Low Carbon Transportation in Emerging Countries; Elsevier: Amsterdam, The Netherlands, 2019.

30. Brůhová Foltýnová, H.; Jordová, R. The contribution of different policy elements to sustainable urban mobility. Transp. Res. Procedia 2014, 4, 312-326. [CrossRef]

31. Marsden, G.; Reardon, L. Questions of governance: Rethinking the study of transportation policy. Transp. Res. Part A 2017, 101, 238-251. [CrossRef]

32. Emberger, G.; May, A. Challenges in the development of national policies on transport. Eur. Transp. Res. Rev. 2017, 9, 55. [CrossRef]

33. May, A.; Boehler-Baedecker, S.; Delgado, L.; Durlin, T.; Enache, M.; van der Pas, J.W. Appropriate national policy frameworks for sustainable urban mobility plans. Eur. Transp. Res. Rev. 2017, 9, 7. [CrossRef]

34. Hilty, L.; Arnfalk, P.; Erdmann, L.; Goodman, J.; Lehmann, M.; Wäger, P. The relevance of information and communication technologies for environmental sustainability. A prospective simulation study. Environ. Model. Softw. 2006, 21, 1618-1629. [CrossRef]

35. Kramers, A.; Höjer, M.; Lövehagen, N.; Wangel, J. Smart sustainable cities-Exploring ICT solutions for reduced energy use in cities. Environ. Model. Softw. 2014, 56, 52-62. [CrossRef]

36. Battarra, R.; Gargiulo, C.; Tremiterra, M.; Zucaro, F. Smart mobility in Italian metropolitan cities: A comparative analysis through indicators and actions. Sustain. Cities Soc. 2018, 41, 556-567. [CrossRef]

37. Garau, C.; Pavan, M.V. Evaluating Urban Quality: Indicators and Assessment Tools for Smart Sustainable Cities. Sustainability 2018, 10, 575. [CrossRef]

38. Lyons, G. Getting smart about urban mobility-Aligning the paradigms of smart and sustainable. Transp. Res. Part A 2018, 115, 4-14. [CrossRef]

39. Ryeng, E.O.; Lindseth, E.M.; Haugen, T. Traffic flow with autonomous vehicles in real-life traffic situations. In Autonomous Vehicles and Future Mobility; Coppola, P., Esztergár-Kiss, D., Eds.; Elsevier: Amsterdam, The Netherlands, 2019; pp. $33-41$.

40. Dell'olio, L.; Ibeas, A.; Cecín, P. Modelling user perception of bus transit quality. Transp. Policy 2010, 17, 388-397. [CrossRef]

41. Coppola, P.; Silvestri, F. Assessing travelers' safety and security perception in railway stations. Case Stud. Transp. Policy 2020, 8, 1127-1136. [CrossRef]

42. Karlaftis, M.G.; Golias, J.; Papadimitriou, E. Transit quality as an integrated traffic management strategy: Measuring perceived service. J. Publ. Transp. 2001, 4, 27-44. [CrossRef]

43. Singleton, P.A.; Wang, L. Safety and Security in Discretionary Travel Decision Making: Focus on Active Travel Mode and Destination Choice. Trans. Res. Rec. 2014, 2430, 47-58. [CrossRef]

44. Hurtado Stieninger, P. From Sustainable Cities to Sustainable People-Changing Behavior Towards Sustainability with the Five A Planning Approach. In Handbook of Sustainability and Social Science Research, World Sustainability; Springer International Publishing: Cham, Switzerland, 2018; pp. 424-426.

45. Thynell, M.; Mohan, D.; Tiwari, G. Sustainable transport and the modernisation of urban transport in Delhi and Stockholm. Cities 2010, 27, 421-429. [CrossRef] 
46. Hall, R.; Sussman, J. Sustainable Transportation: A Strategy for System Change; Working Paper Series ESD-WP-2004-02; Massachusetts Institute of Technology Engineering Systems Division: Cambridge, MA, USA, 2004; Available online: https://www.researchgate. net/publication/247685947 (accessed on 20 January 2021).

47. Jones, H.; Moura, F.; Domingos, T. Transport Infrastructure Project Evaluation Using Cost-benefit Analysis. Procedia Soc. Behav. Sci. 2014, 111, 400-409. [CrossRef]

48. Freeman, R.E. Strategic Management: A Stakeholder Approach; Basic Books: New York, NY, USA, 1984.

49. May, A.; Karlstrom, A.; Marler, N.; Matthews, B.; Minken, H.; Monzon, A.; Page, M.; Pfaffenbichler, P.; Shepherd, S. The Decision Makers' Guidebook (from Projects: PROSPECTS and PLUME). 2005. Available online: https:/ /www.researchgate.net/ publication/241745361_A_Decision_Makers \T1 \textquoteright_Guidebook (accessed on 25 March 2021).

50. Richards, C.; Blackstock, K.; Carter, C. Practical Approaches to Participation. SERG Policy Brief. Number 1. Macaulay Institute, 2007, 2nd edition. Available online: https:/ / macaulay.webarchive.hutton.ac.uk/ruralsustainability/SERG\%20PB1\%20final.pdf (accessed on 6 January 2021).

51. Mladenovic, G.; Vajdic, N.; Wündsch, B.; Temeljotov Salaj, A. Use of key performance indicators for PPP transport projects to meet stakeholders' performance objectives. Built Environ. Proj. Asset Manag. 2013, 3, 228-249. [CrossRef]

52. Brugha, R.; Varvasovszky, Z. Stakeholder analysis: A review. Health Policy Plan. 2000, 15, 239-246. [CrossRef]

53. Emberger, G.; Pfaffenbichler, P.; Jaensirisak, S.; Timms, P. “Ideal” decision-making processes for transport planning: A comparison between Europe and South East Asia. Transp. Policy 2008, 15, 341-349. [CrossRef] 